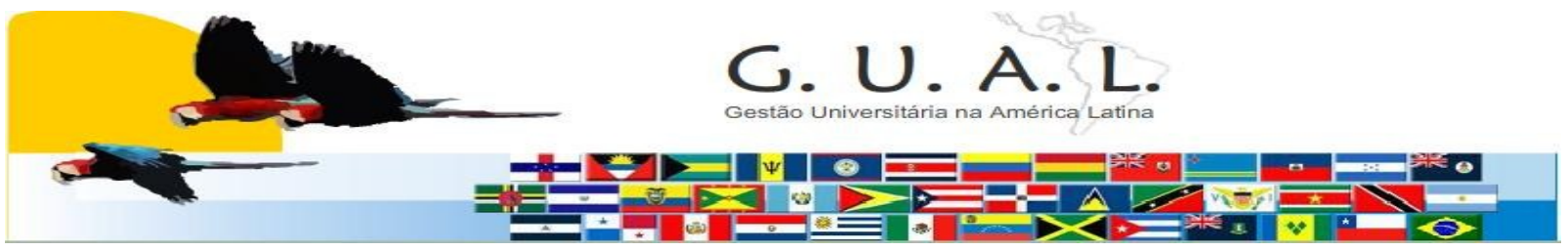

ISSN 1983-4535

\title{
A IMPORTÂNCIA DA TRANSPARÊNCIA NA GESTÃO DE RECURSOS PÚBLICOS, EM FUNDAÇÕES DE APOIO A PESQUISA E EXTENSÃO
}

\author{
Taiane Lemõns Gonçalves, Especialista \\ Universidade Federal do Rio Grande \\ tlgoncalves@hotmail.com \\ Alexandre Costa Quintana, Mestre \\ Universidade Federal do Rio Grande \\ quintana@vetorial.net
}

\begin{abstract}
RESUMO
Em virtude do crescimento do Terceiro Setor, o presente trabalho possui como objetivo, evidenciar a importância da transparência nas entidades por ele abrangidas, tendo em vista que estas instituições além de serem financiadas por empresas privadas, também recebem e administram recursos públicos. O Terceiro Setor abrange as entidades sem finalidade lucrativa e que visam o interesse da coletividade. O foco do estudo são as Fundações de Apoio a Instituições de Ensino Superior. A metodologia utilizada para o desenvolvimento do trabalho é de natureza aplicada por tratar-se de uma pesquisa de campo e analisar os sites e Relatórios de Gestão das Fundações de Apoio em busca de dados que evidenciem a transparência de suas ações. Com relação aos objetivos é exploratória e descritiva, quanto aos procedimentos é documental e de campo e a abordagem do problema é desempenhada sob o aspecto qualitativo. Visto que as entidades analisadas desempenham serviços de cunho social e que grande parte da população não possui acesso à internet, a divulgação das atividades exercidas e dos resultados alcançados deveria ser realizada em meios de comunicação acessíveis para a sociedade em geral. Os resultados apontaram um número significativo de projetos e recursos públicos administrados pelas Fundações de Apoio, sendo assim, constatou-se que o controle social é fundamental e que as informações expostas nos sites das fundações, deveriam ser demonstradas de forma mais objetiva e clara, possibilitando a análise e entendimento de todos interessados.
\end{abstract}

Palavras-chave: Terceiro setor. Transparência. Fundação de apoio. 


\section{A IMPORTÂNCIA DA TRANSPARÊNCIA NA GESTÃO DE RECURSOS PÚBLICOS, EM FUNDAÇÕES DE APOIO A PESQUISA E EXTENSÃO}

\section{INTRODUÇÃO}

O Terceiro Setor abrange as entidades privadas, sem finalidade lucrativa, que visam o bem comum do coletivo. Pode-se citar dentre estas instituições os Serviços Sociais Autônomos, as Organizações Sociais e as Organizações da Sociedade Civil de Interesse Público - OSCIP.

Em virtude dos serviços públicos apresentarem carência em diversas áreas, o Terceiro Setor aparece como um forte parceiro do governo na prestação de vários serviços.

Tendo em vista que as entidades do Terceiro Setor, são financiadas em sua grande maioria por recursos públicos, é de extrema importância a transparência destas instituições na administração de seus recursos.

As Organizações Sociais abrangem dentre outras instituições, as fundações, que são entidades jurídicas com o patrimônio como fator preponderante. O patrimônio das fundações deve ser administrado de modo a atingir os objetivos da instituição determinados pelo seu instituidor e previstos em seu estatuto.

O tipo de entidade foco deste trabalho é a Fundação de Apoio a Instituições de Ensino Superior, que é aquela instituída por pessoas físicas ou jurídicas com o objetivo de auxiliar e administrar projetos de pesquisa, ensino e extensão das universidades federais e demais instituições de ensino superior.

Para o gerenciamento de projetos, as fundações de apoio recebem financiamento de instituições públicas e privadas e por este fato se torna fundamental o controle e fiscalização destas entidades pelo Estado, bem como pela sociedade em geral.

O objetivo deste artigo é evidenciar a importância da transparência nas organizações do Terceiro Setor, tendo em vista que estas instituições além de serem financiadas por empresas privadas, também recebem e administram recursos públicos.

Justifica-se a realização deste estudo, em virtude do crescimento constante e progressivo do Terceiro Setor e pela importância da atuação deste setor na economia. Desta forma, em virtude da expansão do Terceiro Setor, torna-se fundamental que o Estado, bem como a sociedade em geral tenha consciência e controle a respeito da forma como são administrados os recursos públicos repassados às entidades incluídas neste setor. 


\section{A IMPORTÂNCIA DA TRANSPARÊNCIA NA GESTÃO DE RECURSOS PÚBLICOS, EM FUNDAÇÕES DE APOIO A PESQUISA E EXTENSÃO}

\section{SETORES DA ECONOMIA}

A economia divide-se basicamente em três setores. O governo é considerado o Setor Primário; o Mercado classifica-se por Setor Secundário e o Terceiro Setor é aquele sem finalidades lucrativas que tem por objetivo o benefício da coletividade.

Segundo Rafael (1997, p.26) tem-se, "no Primeiro Setor, a Administração Pública, dividida nos mais variados órgãos com a finalidade de gerir, guardar, conservar e aprimorar todos os bens, interesses e serviços da coletividade, para bem servir a todos os cidadãos”. Em qualquer país, o setor governamental é considerado o primeiro setor da economia.

Para Coelho apud Bettiol Júnior e Varela (2006, p.4) o Governo ou Primeiro Setor "distingui-se, sobretudo, pelo fato de legitimar e organizar suas ações por meio de poderes coercitivos".

Já o Segundo Setor, conforme Rafael (1997), é o setor produtivo dos países essencialmente capitalistas. Neste setor estão incluídas as indústrias, as empresas comerciais, as entidades agrícolas, enfim, toda entidade produtiva com a finalidade lucrativa.

De acordo com Coelho apud Bettiol Júnior e Varela (2006, p.4) “comparativamente ao Governo, o mercado atua sob o princípio da não coerção legal, ou seja, os clientes têm liberdade para escolher o que e onde comprar". As entidades mercantis são instituições com finalidade lucrativa e representam o Segundo Setor da Economia.

As entidades de fins sociais são representantes do Terceiro Setor e abrangem uma ampla variedade de instituições privadas atuantes em diversas áreas de interesse público (CFC, 2008). O Terceiro Setor é aquele que inclui entidades jurídicas não-governamentais, que visam o bem da coletividade, sem objetivo lucrativo.

\subsection{Terceiro setor e filantropia}

Segundo Branco (1997, p.5) “o setor filantrópico passou a existir legalmente no Brasil nos anos 30, na era da centralização e autoritarismo em que o estado assumiu a responsabilidade pela provisão de serviços sociais".

Os fatores influentes do relacionamento entre as instituições sem fins lucrativos e o governo federal foi o acesso a recursos públicos por meio do Conselho Nacional de Serviço Social - CNSS, instituído em 1938, bem como isenções e incentivos fiscais concedidos a estas entidades. 


\section{A IMPORTÂNCIA DA TRANSPARÊNCIA NA GESTÃO DE RECURSOS PÚBLICOS, EM FUNDAÇÕES DE APOIO A PESQUISA E EXTENSÃO}

De acordo com Nunes (2006, p.21), "no Brasil, a presença da Filantropia começa a se identificar através das Santas Casas e institutos de beneficiência, influência do forte espírito católico de nossos colonizadores, que direcionou nossa caridade e uma diretriz corporativa".

A Igreja foi a protagonista das instituições filantrópicas, por meio das Pastorais católicas e das comunidades eclesiais de base nas décadas de 60 e 70, dando origem às Organizações Não-Governamentais - ONGs no Brasil. Estas organizações foram as precursoras do Terceiro Setor no Brasil, abrangendo vários tipos de instituições.

De acordo com Castro (2008) o Terceiro Setor faz a ligação entre o Primeiro Setor (Estado) e o Segundo Setor (Mercado) contemplando as organizações da sociedade civil de fins não-lucrativos e públicos.

A respeito do Terceiro Setor, Paes (2001, p.69) explica que:

Em termos de direito brasileiro, configuram-se entidades do Terceiro Setor, ou ONGs, as entidades de interesse social sem fins lucrativos, como associações, as sociedades e as fundações de direito privado, com autonomia e administração própria, cujo objetivo é o atendimento de alguma necessidade social ou a defesa de direitos difusos ou emergentes.

Para Nunes (2006), o Terceiro Setor pode ser definido como o conjunto de organizações de origem privada, dotadas de autonomia, administração própria e sem fins lucrativos, com o objetivo de promover o bem-estar social por meio de ações assistenciais, culturais e de promoção da cidadania.

\subsubsection{Entidades Componentes do Terceiro Setor}

O Terceiro Setor abrange as organizações abaixo relacionadas:

\section{- Serviços Sociais Autônomos}

Para Castro (2008) são entidades com personalidade jurídica de direito privado, sem fins lucrativos, instituídas por lei e com o intuito de assistir a certos grupos profissionais ou categorias sociais.

As instituições desta categoria atuam em cooperação com a Administração Pública e apesar de serem autorizadas pelo Governo, não fazem parte da Administração Pública Indireta ou Descentralizada (PETER e MACHADO, 2003). 


\section{A IMPORTÂNCIA DA TRANSPARÊNCIA NA GESTÃO DE RECURSOS PÚBLICOS, EM FUNDAÇÕES DE APOIO A PESQUISA E EXTENSÃO}

Estas organizações são mantidas por contribuições parafiscais e pode-se citar como exemplo, as entidades do Sistema "S”, Serviço Social da Indústria -SESI, Serviço Social do Comércio - SESC, Serviço Nacional de Aprendizagem Industrial - SENAI e Serviço Brasileiro de Apoio às Micro e Pequenas Empresas - SEBRAE.

\section{- Organização da Sociedade Civil de Interesse Público (OSCIP)}

A Lei 9.790, de 23 de março de 1999, regula o título de OSCIP e em seu art. $3^{\circ}$ descreve quais finalidades as instituições precisam estabelecer, para se enquadrarem nesta titulação, conforme evidenciado a seguir:

Art. $3^{\circ}$ A qualificação instituída por esta Lei, observado em qualquer caso, o princípio da universalização dos serviços, no respectivo âmbito de atuação das Organizações, somente será conferida às pessoas jurídicas de direito privado, sem fins lucrativos, cujos objetivos sociais tenham pelo menos uma das seguintes finalidades:

I - promoção da assistência social;

II - promoção da cultura, defesa e conservação do patrimônio histórico e artístico;

III - promoção gratuita da educação, observando-se a forma complementar de participação das organizações de que trata esta Lei;

IV - promoção gratuita da saúde, observando-se a forma complementar de participação das organizações de que trata esta Lei;

$\mathrm{V}$ - promoção da segurança alimentar e nutricional;

VI - defesa, preservação e conservação do meio ambiente e promoção do desenvolvimento sustentável;

VII - promoção do voluntariado;

VIII - promoção do desenvolvimento econômico e social e combate à pobreza;

IX - experimentação, não lucrativa, de novos modelos sócio-produtivos e de sistemas alternativos de produção, comércio, emprego e crédito;

$\mathrm{X}$ - promoção de direitos estabelecidos, construção de novos direitos e assessoria jurídica gratuita de interesse suplementar;

XI - promoção da ética, da paz, da cidadania, dos direitos humanos, da democracia e de outros valores universais;

XII - estudos e pesquisas, desenvolvimento de tecnologias alternativas, produção e divulgação de informações e conhecimentos técnicos e científicos que digam respeito às atividades mencionadas neste artigo.

Parágrafo único. Para os fins deste artigo, a dedicação às atividades nele previstas configura-se mediante a execução direta de projetos, programas, planos de ações correlatas, por meio da doação de recursos físicos, humanos e financeiros, ou ainda pela prestação de serviços intermediários de apoio a outras organizações sem fins lucrativos e a órgãos do setor público que atuem em áreas afins. 


\section{A IMPORTÂNCIA DA TRANSPARÊNCIA NA GESTÃO DE RECURSOS PÚBLICOS, EM FUNDAÇÕES DE APOIO A PESQUISA E EXTENSÃO}

De acordo com Castro (2008) são entidades com os mesmos moldes das Organizações Sociais, mas a vinculação com a Administração Pública é feita por meio de "Termo de Parceria", permitindo que estas organizações realizem atividades autorizadas pelo Estado. As OSCIP's são consideradas de utilidade pública por força da lei que as criou.

\section{- Organizações Sociais (OS)}

São instituições criadas por iniciativa de particulares, sem fins lucrativos, são pessoas jurídicas de direito privado, com a finalidade de desempenhar serviços sociais que não tenham a exclusividade do Estado. O Poder Público incentiva e fiscaliza as Organizações Sociais, por meio de vínculo jurídico instituído mediante "contrato de gestão" e é por meio deste contrato que a Administração Pública repassa recursos de seu orçamento, controlando os resultados (CASTRO, 2008).

Para Paes (2001) as organizações sociais objetivam ser um modelo de parceria entre o Estado e a sociedade, mas não constituem uma nova pessoa jurídica; são inseridas no âmbito das pessoas jurídicas já existentes sob a forma de sociedades civis, associações civis e fundações, todas sem finalidade lucrativa.

\subsection{Fundações}

Conforme explicam Peter e Machado (2003) na iniciativa privada podem ser criadas entidades sob a forma de fundações, entretanto não se integram à Administração Pública por não subordinarem-se à supervisão ministerial e por não serem criadas por lei.

De acordo com Resende (2006, p.43) “a Fundação de natureza jurídica de direito privado, tem seu nascimento com a inscrição de seu estatuto e da escritura de instituição, no registro civil das pessoas jurídicas, após aprovação do Ministério Público”.

As fundações, pessoas jurídicas que têm suporte factual no patrimônio inicial, em razão de suas características específicas (modo de constituição, administração e representação) poderão pertencer a um ou outro ramo do direito.

Para Szazi (2006, p.37) Fundação é "um patrimônio destinado a servir, sem intuito de lucro, a uma causa de interesse público determinada, que adquire personificação jurídica por iniciativa de seu instituidor". O patrimônio deve ser suficiente para a manutenção da entidade e manutenção dos fins previstos em Estatuto. 


\section{A IMPORTÂNCIA DA TRANSPARÊNCIA NA GESTÃO DE RECURSOS PÚBLICOS, EM FUNDAÇÕES DE APOIO A PESQUISA E EXTENSÃO}

Resende (2006) explica que diferentemente das demais pessoas jurídicas, Fundação é um patrimônio com um fim determinado que adquire personalidade jurídica, por força de lei.

\subsubsection{Fundações de Apoio a Instituições de Ensino Superior}

As fundações são divididas em vários tipos de entidades, o tipo de fundação abordado neste trabalho são as Fundações de Apoio a instituições de ensino superior.

$\mathrm{O}$ art. $1^{\circ}$ da lei 8958/94 define o seguinte a respeito das Fundações de Apoio:

As Instituições Federais de Ensino Superior - IFES, bem como as Instituições Científicas e Tecnológicas - ICTs, sobre as quais dispõe a Lei $\mathrm{n}^{\mathrm{o}}$ 10.973 , de 2 de dezembro de 2004, poderão realizar convênios e contratos, nos termos do inciso XIII do art. 24 da Lei no ${ }^{\circ}$ 8.666, de 21 de junho de 1993, por prazo determinado, com fundações instituídas com a finalidade de dar apoio a projetos de ensino, pesquisa e extensão e de desenvolvimento institucional, científico e tecnológico, inclusive na gestão administrativa e financeira estritamente necessária à execução desses projetos. (Redação dada pela Lei ${ }^{\circ} 12.349$, de 2010)

De acordo com Paes (2001) as Fundações de apoio a instituições de ensino superior são fundações de direito privado, instituídas por pessoas físicas ou jurídicas, visando dar auxílio e fomentar os projetos de pesquisa, ensino e extensão das universidades federais e demais instituições de ensino superior, públicas ou privadas.

Segundo Alves e Azevedo (2007), as Fundações de Apoio por abreviar caminhos administrativos, estimulam mudanças na burocracia universitária, internamente, deslocam o poder gerencial no organograma oficial da universidade e respondem a instâncias mais ágeis do Estado (Ministério Público).

Quanto à finalidade das fundações de apoio, Tristão (2000, p.6) salienta que:

É oportuno alertar que não devem ser permitidos desvios de finalidade no apoio fundacional, com utilização de parte de seus recursos para suplementação salarial de professores e servidores técnico-administrativos sem a contraprestação de serviços específicos em projetos ou atividades das fundações.

Resende (2006) explica que com relação às Fundações de Apoio, mais importante do que discutir a respeito dos relevantes serviços por elas prestados às Universidades, é a busca de regras que assegurem o funcionamento constitucional, bem como a procura de meios 
legítimos para que com autonomia e independência as instituições de apoio e apoiadas, desempenhem suas atividades de forma transparente e definida.

\subsubsection{Formas de Financiamento ao Terceiro Setor}

Branco (1997, p.2) relata que "as entidades do Terceiro Setor são financiadas tanto por cessões, doações e contribuições privadas como por subvenções governamentais e frequentemente são contempladas com incentivos fiscais em função do interesse público de sua ação".

A seguir serão abordadas algumas modalidades de financiamento às instituições do Terceiro Setor.

\section{- Convênios}

No convênio, se o conveniado recebe determinado valor, este fica vinculado à utilização prevista no ajuste; assim, se um particular recebe verbas do poder público em decorrência de convênio, estes valores só podem ser utilizados para fins previstos no convênio, pois se não perdem a característica de dinheiro público. (DI PIETRO APUD CFC, 2008).

Já o Decreto 6170, em seu artigo $1^{\circ}, \S 1^{\circ}$ estabelece o seguinte a respeito de Convênio:

Acordo, ajuste ou qualquer outro instrumento que discipline a transferência de recursos financeiros de dotações consignadas nos Orçamentos Fiscal e da Seguridade Social da União e tenha como partícipe, de um lado, órgão ou entidade da administração pública federal, direta ou indireta, e, de outro lado, órgão ou entidade da administração pública estadual, distrital ou municipal, direta ou indireta, ou ainda, entidades privadas sem fins lucrativos, visando a execução de programa de governo, envolvendo a realização de projeto, atividade, serviço, aquisição de bens ou evento de interesse recíproco, em regime de mútua cooperação.

Os Convênios administrativos são acordos firmados por entidades públicas de qualquer espécie, ou entre estas e organizações particulares (PAES, 2001).

\section{- Contratos}

Segundo Meirelles apud Paes (2001, p.434), "contrato é todo acordo de vontades, firmado livremente pelas partes para criar obrigações e direitos recíprocos".

Rev. GUAL., Florianópolis, v.4, n. 2, p. 123-145, mai/ago. 2011 


\section{A IMPORTÂNCIA DA TRANSPARÊNCIA NA GESTÃO DE RECURSOS PÚBLICOS, EM FUNDAÇÕES DE APOIO A PESQUISA E EXTENSÃO}

O contrato é constituído de vontades que se compõem, mas possuem interesses antagônicos, essa é a característica principal na diferenciação entre convênio e contrato.

De acordo com Szazi (2006, p.108) “o contrato pressupõe, de um lado, o interesse do poder público na aquisição do bem ou serviço e, de outro, o recebimento de uma importância em dinheiro".

\section{- Contribuições}

De acordo com Nunes (2006, p.75), "transferências correntes ou de capital concedidas em virtude de lei, destinadas às pessoas de direito público ou privado sem finalidade lucrativa, e sem a exigência de contraprestação direta de bens e serviços". Os auxílios são um exemplo de contribuições, que podem ser consubstanciadas em inversões financeiras ou investimentos.

Segundo Bettiol Júnior e Varela (2006, p.5) “contribuições são transferências voluntárias e incondicionais de ativos para uma entidade (beneficiária) advinda de outra entidade que não espera receber valor em troca e não age como proprietário (doador)”.

\subsection{Controle e fiscalização do terceiro setor}

Controle é instrumento de gestão que permite proteger os ativos, disciplinar o relacionamento dos agentes de execução com atividades, orientar a elaboração de informação confiável, acompanhar e criticar o desempenho das atividades. (CFC, 2008).

Segundo Nunes (2006, p.57) "aquilo que o Governo repassa e deixa de arrecadar com entidades sociais precisa, efetivamente, ser transformado em benefícios para a população". Por este motivo o controle estatal e social sob as entidades do Terceiro Setor é de suma importância, tendo em vista que estas instituições administram significativa parcela de recursos públicos na consecução de seus objetivos.

\subsubsection{Controle Interno}

O controle interno das instituições do Terceiro Setor deve ser feito por meio de um Conselho Fiscal previsto no estatuto da entidade, bem como a capacitação de seus dirigentes e ainda pela organização contábil destas entidades.

A ação do controle interno nas entidades componentes do Terceiro Setor tem o objetivo de controlar o patrimônio, zelar pelo cumprimento estatutário e pelas determinações 
das autoridades nos âmbitos federal, estadual e municipal, bem como verificar o cumprimento de contratos e acordos (CFC, 2008).

Segundo Paes, Conselho Fiscal é:

É o órgão que na estrutura da administração da entidade fundacional tem como competência a fiscalização da gestão econômico-financeira da fundação, devendo para tanto, examinar suas contas, balanços e quaisquer outros documentos e emitir, ao final desta análise parecer contábil, que deverá ser no mínimo anual (podendo ser em menos tempo, se as circunstâncias e os fatos assim o exigirem) (PAES, 2001, p. 250).

No que diz respeito à Contabilidade, Assis, Mello e Slomski (2006, p. 6) ressaltam o seguinte:

A Contabilidade deve auxiliar as entidades do Terceiro Setor no processo de accountability, ou seja, devem ser fornecidas as informações necessárias para que os investidores sociais possam verificar o montante de recursos recebido pelas entidades, bem como, a destinação destes recursos e, consequentemente, os resultados alcançados.

De acordo com o CFC (2008, p. 88) "além das demonstrações convencionais, como Balanço Patrimonial, Demonstração do Superávit ou Déficit do Exercício e Demonstração do Patrimônio Social a entidade poderá elaborar outras demonstrações de natureza gerencial”.

A perpetuidade e continuidade das fundações não dependem somente da boa administração de seu patrimônio, mas também da qualidade dos projetos que realiza no sentido de alcançar seus objetivos.

\subsubsection{Controle Estatal}

Dentro do controle estatal, pode-se destacar a atuação do Tribunal de Contas da União - TCU, da Controladoria Geral da União - CGU e ainda do Ministério Público. Tais órgãos serão descritos a seguir.

\section{- Tribunal de Contas da União - TCU}

Peter e Machado (2003) expõem que a constituição de 1934 atribuiu ao TCU o registro prévio das despesas e contratos, o acompanhamento da execução orçamentária, a elaboração de parecer prévio sobre as contas do Presidente da República e o julgamento das contas dos responsáveis por bens e dinheiros públicos. 


\section{A IMPORTÂNCIA DA TRANSPARÊNCIA NA GESTÃO DE RECURSOS PÚBLICOS, EM FUNDAÇÕES DE APOIO A PESQUISA E EXTENSÃO}

O Tribunal de Contas é um representante do controle estatal exercido sobre as entidades do Terceiro Setor, mas sua fiscalização a estas entidades é realizada de forma indireta.

Segundo Nunes (2006) a prestação de contas ao Tribunal de Contas, não pode ser apreciada por este órgão sem antes passar pelo Controle Interno do órgão competente e pelo ordenador da despesa.

\section{- Controladoria Geral da União - CGU}

Para Peter e Machado (2003, p.31), “a Controladoria Geral da União é o órgão central do Sistema de Controle Interno do Poder Executivo Federal, incumbido da orientação normativa e supervisão técnica dos órgãos que compõem o sistema”.

\section{- Controle Estatal pelo Ministério Público}

De acordo com o art. 127 da Constituição da República "O Ministério Público é instituição permanente, essencial à função jurisdicional do Estado, incumbindo-lhe a defesa da ordem jurídica, do regime democrático e dos interesses sociais e individuais indisponíveis".

Kohama (2000, p.44) ressalta que “as fundações não dispensam a fiscalização institucional do Ministério Público, que velará pela observância de seus Estatutos e denunciará as irregularidades ao órgão estatal a que estiver vinculada”.

Segundo Rafael (1997) o Ministério Público tem o encargo de zelar pelas fundações existentes na comarca, e por esta razão tem o dever de fiscalizar os atos dos administradores, possuindo autoridade de anular aqueles atos praticados em desacordo com o estatuto, regimento interno, norteador da entidade.

\subsubsection{Transparência e Controle Social}

O controle social só se torna efetivo por meio da transparência da gestão e o acesso à informação. Para Resende (2006, p.138) "a transparência, accountability ou o exercício do controle social pode e deve ser exercido por meio da elaboração e divulgação de relatórios das atividades desenvolvidas pela entidade, inserida no contexto do Terceiro Setor". 


\section{A IMPORTÂNCIA DA TRANSPARÊNCIA NA GESTÃO DE RECURSOS PÚBLICOS, EM FUNDAÇÕES DE APOIO A PESQUISA E EXTENSÃO}

De acordo com Nunes (2006) transparência significa a divulgação dos atos de gestão, relatórios, resultados dos exercícios financeiros, demonstrações contábeis e financeiras, dentre outros relatórios em linguagem clara e acessível, sendo o acesso à informação o complemento desta transparência.

A forma de divulgação da informação é de suma importância, tendo em vista que deve estar disponível em meios que toda a sociedade tenha acesso. De acordo com Assis, Mello e Slomski (2006, p.6) "a transparência para o Terceiro Setor é fator preponderante da sua sobrevivência, é preciso que estas entidades prestem contas dos seus atos aos investidores sociais".

As entidades do Terceiro Setor podem ter na transparência uma grande aliada, tendo em vista que por se tratarem de instituições com finalidade social, adquirem credibilidade se suas ações e resultados forem disponibilizados a todos os interessados.

\subsubsection{Prestação de Contas}

De acordo com regulamentação estabelecida em atos da administração superior dos Ministérios Públicos e resoluções emanadas por Procuradorias-Gerais de Justiça de cada Estado da Federação, as fundações possuem a obrigatoriedade de prestar contas anualmente ao Ministério público, representado pelas Curadorias de Fundações de cada comarca (RESENDE, 2006).

De acordo com Assis, Mello e Slomski (2006, p.7) "a prestação de contas, por parte das entidades de terceiro setor, à sociedade e aos doadores de recursos possibilitará um aumento da transparência de suas ações e da confiança perante a sociedade".

Resende (2006) ainda relata que por meio de metodologia desenvolvida por pesquisadores da Fundação Instituto de Pesquisas Econômicas (FIPE), surgiu o Sistema de Cadastro e Prestação de Contas - SICAP que é um instrumento de coleta de dados e informações utilizado por diversos Ministérios Públicos estaduais (Rio Grande do Sul, Santa Catarina, Paraná, São Paulo, Minas Gerais, Espírito Santo, Mato Grosso do Sul, Bahia, Alagoas, Pernambuco, Paraíba, Rio Grande do Norte, Piauí, Maranhão, Tocantins, Pará, Roraima e Acre), no velamento das Fundações e das entidades de interesse social (associações).

Rev. GUAL., Florianópolis, v.4, n. 2, p. 123-145, mai/ago. 2011 


\section{A IMPORTÂNCIA DA TRANSPARÊNCIA NA GESTÃO DE RECURSOS PÚBLICOS, EM FUNDAÇÕES DE APOIO A PESQUISA E EXTENSÃO}

A Portaria Interministerial $\mathrm{MP} / \mathrm{MF} / \mathrm{MCT} \mathrm{n}^{\circ} 127$, dispõe sobre normas relativas às transferências de recursos da União mediante convênios e contratos de repasse e em seu art. 56 , ressalta o seguinte em relação à prestação de contas:

O órgão ou entidade que receber recursos na forma estabelecida nesta Portaria estará sujeito a prestar contas de sua boa e regular aplicação no prazo máximo de trinta dias contados do término da vigência do convênio ou contrato ou do último pagamento efetuado, quando este ocorrer em data anterior àquela do encerramento da vigência.

$\S 1^{\circ}$ Quando a prestação de contas não for encaminhada no prazo estabelecido no caput, o concedente ou contratante estabelecerá o prazo máximo de trinta dias para sua apresentação, ou recolhimento dos recursos, incluídos os rendimentos da aplicação no mercado financeiro, atualizados monetariamente e acrescido de juros de mora na forma da lei.

$\S 2^{\circ} \mathrm{Se}$, ao término do prazo estabelecido, o convenente ou contratado não apresentar prestação de contas nem devolver os recursos nos termos do $\S 1^{\circ}$, o concedente registrará a inadimplência no SICONV por omissão do dever de prestar contas e comunicará o fato ao órgão de contabilidade analítica a que estiver vinculado, para fins de instauração de tomada de contas sob aquele argumento de adoção de outras medidas para reparação de dano ao erário, sob pena de responsabilização solidária.

Independentemente da obrigação de prestar contas anualmente ao Ministério Público, as Fundações de Apoio ficam condicionadas a apresentar prestação de contas da execução dos projetos sob sua administração, aos órgãos públicos financiadores que repassam verbas por meio de convênios e contratos de repasse.

\section{METODOLOGIA}

O método utilizado na pesquisa é o dedutivo, tendo em vista que este estudo aborda as Fundações de Apoio à Instituições de Ensino Superior como um assunto específico dentro de um grande grupo que é o Terceiro Setor.

A presente pesquisa classifica-se como aplicada, visto que realiza uma pesquisa de campo tomando por base Relatórios de Gestão das Atividades de Fundações de Apoio, no intuito de verificar o montante de recursos públicos administrados por estas instituições.

Quanto aos objetivos a pesquisa é Exploratória e Descritiva. A pesquisa exploratória é aquela que tem por objetivo proporcionar a familiarização com o problema, a fim de construir hipóteses ou torná-lo mais explicito (SILVA, 2008). Já a pesquisa descritiva é a que tem a finalidade de observar, descrever, analisar, classificar e registrar fatos sem qualquer tipo de 


\section{A IMPORTÂNCIA DA TRANSPARÊNCIA NA GESTÃO DE RECURSOS PÚBLICOS, EM FUNDAÇÕES DE APOIO A PESQUISA E EXTENSÃO}

interferência. (FURASTÉ, 2008). O presente trabalho visa buscar o aprofundamento no estudo do Terceiro Setor, bem como de seus órgãos fiscalizadores, caracterizando a pesquisa como exploratória e ainda procura descrever e analisar suas principais características, fator este que classifica a pesquisa também como descritiva.

Classifica-se a presente pesquisa como documental, tendo em vista que o objeto de estudo são os Relatórios de atividades das Fundações de Apoio, é classificada ainda como pesquisa de campo, pois visa à análise destes relatórios com o intuito de quantificar em números e percentuais os recursos públicos administrados por tais entidades.

Quanto à abordagem do problema, a pesquisa utilizada neste trabalho é qualitativa, tendo em vista que não se utiliza de dados estatísticos em sua execução, apenas analisa a informação descrita nos relatórios das Fundações.

\section{ANÁLISE DOS RESULTADOS}

A pesquisa foi realizada a fim de constatar quais tipos de informações e dados são disponibilizados pelas Fundações de Apoio a Instituições de Ensino Superior, no sentido de averiguar o montante de recursos públicos administrados, bem como de evidenciar a transparência das ações e resultados destas instituições. Assim, foram selecionadas uma Fundação de Apoio de cada região do país. Analisou-se o site das Fundações de Apoio do país credenciadas pelo MEC, sendo que somente as descritas a seguir apresentavam os dados pertinentes para a realização do estudo.

\section{Quadro 1}

Fundações de Apoio a Instituições de Ensino Superior

\begin{tabular}{|c|c|c|}
\hline REGIÃo & FUNDAÇão DE APOIO & SIGLA \\
\hline Nordeste & $\begin{array}{c}\text { Fundação Sousândrade de Apoio ao Desenvolvimento da } \\
\text { Universidade Federal do Maranhão }\end{array}$ & FSADU \\
\hline Norte & Fundação de Apoio Institucional Rio Solimões & UNI-SOL \\
\hline Centro Oeste & Fundação de Apoio a Pesquisa & FUNAPE \\
\hline Sul & Fundação da Universidade Federal do Paraná & FUNPAR \\
\hline Sudeste & $\begin{array}{c}\text { Fundação de Apoio Institucional ao Desenvolvimento } \\
\text { Científico e Tecnológico da Universidade Federal de São } \\
\text { Carlos }\end{array}$ & UFSCar \\
\hline
\end{tabular}

Fonte: Relatórios de Gestão 2007 e Sitio Eletrônico das Fundações de Apoio

Rev. GUAL., Florianópolis, v.4, n. 2, p. 123-145, mai/ago. 2011 


\subsection{Coleta e Análise de Dados}

Tendo em vista que os Relatórios de Gestão são elaborados pelas Fundações de Apoio, sem um padrão definido a respeito do tipo e forma de divulgação das informações, cada entidade possui uma maneira diferenciada de desenvolvê-lo.

Por esta razão, procurou-se identificar nos diversos modelos de Relatórios apresentados, informações que fossem peculiares entre eles e que tivessem relação com o foco da pesquisa.

Visto que a principal atividade desempenhada pelas Fundações de Apoio é o gerenciamento de Projetos de pesquisa, ensino e extensão, a seguir estão descritos o número de Projetos administrados em 2007 pelas entidades analisadas:

Tabela 1 - Projetos Administrados em 2007

\begin{tabular}{ccc} 
FundAÇ̃̃o DE APOIO & NÚMERO DE PROJETOS & PERCENTUAL \\
FUNPAR & 1.013 & $37,87 \%$ \\
FAI-UFSCar & 953 & $35,63 \%$ \\
UNI-SOL & 276 & $10,32 \%$ \\
FUNAPE & 221 & $8,26 \%$ \\
FSADU & 212 & $7,92 \%$ \\
\hline TOTAL & $\mathbf{2 . 6 7 5}$ & $\mathbf{1 0 0 \%}$
\end{tabular}

Fonte: Relatórios de Gestão das Fundações de Apoio

De acordo com a Tabela 1, evidenciou-se que com 37,87\% a FUNPAR foi a instituição com maior movimentação de projetos no ano de 2007. Logo em seguida a FAIUFSCar apresentou um percentual de 35,63 do total. As demais entidades somaram 26,5\%.

Do total de Projetos administrados, procurou-se averiguar a identificação de Projetos Públicos, conforme demonstrados a seguir:

Tabela 2 - Projetos Públicos Administrados em 2007

\begin{tabular}{ccc} 
FUNDAÇÃO DE APOIO & NÚMERO DE PROJETOS & PERCENTUAL \\
FUNPAR & 342 & $44,71 \%$ \\
FSADU & 199 & $26,01 \%$ \\
FAI-UFSCar & 150 & $19,61 \%$ \\
UNI-SOL & 74 & $9,67 \%$ \\
FUNAPE & - & - \\
\hline TOTAL & $\mathbf{7 6 5}$ & $\mathbf{1 0 0 \%}$
\end{tabular}

Fonte: Relatórios de Gestão das Fundações de Apoio 


\section{A IMPORTÂNCIA DA TRANSPARÊNCIA NA GESTÃO DE RECURSOS PÚBLICOS, EM FUNDAÇÕES DE APOIO A PESQUISA E EXTENSÃO}

Ao analisar a Tabela 2 percebe-se que proporcionalmente ao número total de projetos administrados, a FUNPAR também foi a instituição que gerenciou maior número de projetos públicos. A FUNAPE não apresentou informação relacionada ao número de projetos públicos por ela administrados, em seu Relatório de Gestão. Em compensação pode-se perceber que a FSADU que é a fundação analisada com o menor número de projetos, foi a entidade que apresentou o maior percentual de projetos públicos administrados em relação ao total.

A seguir demonstrou-se a análise dos projetos públicos comparados ao total de projetos de cada instituição.

Tabela 3 - Projetos Públicos x Privados em 2007

\begin{tabular}{cccc}
$\begin{array}{c}\text { FUNDAÇÃO DE } \\
\text { APOIO }\end{array}$ & $\begin{array}{c}\text { NÚMERO DE } \\
\text { PROJETOS }\end{array}$ & $\begin{array}{c}\text { NÚMERO DE } \\
\text { PROJETOS PÚBLICOS }\end{array}$ & PERCENTUAL \\
FUNPAR & 1.013 & 342 & $34 \%$ \\
FAI-UFSCar & 953 & 150 & $16 \%$ \\
UNI-SOL & 276 & 74 & $27 \%$ \\
FUNAPE & 221 & -- & -- \\
FSADU & 212 & 199 & $94 \%$ \\
\hline TOTAL & $\mathbf{2 . 6 7 5}$ & $\mathbf{7 6 5}$ & $\mathbf{2 9 \%}$
\end{tabular}

Fonte: Relatórios de Gestão das Fundações de Apoio

Na tabela 3 procurou-se demonstrar o montante de projetos públicos que cada entidade administrou, tendo por base o seu número total de projetos gerenciados. Neste contexto, evidenciou-se que a FSADU foi a instituição que apresentou o maior percentual de projetos públicos gerenciados, representando quase a totalidade do número de projetos.

Coletou-se também o valor de recursos administrados pelas Entidades:

Tabela 4 - Recursos Gerenciados em 2007

\begin{tabular}{ccc} 
FUNDAÇÃO DE APOIO & TOTAL EM R\$ & PERCENTUAIS \\
FUNPAR & $169.276 .384,01$ & $38,74 \%$ \\
FAI-UFSCar & $100.719 .177,68$ & $23,05 \%$ \\
FUNAPE & $40.048 .386,00$ & $9,16 \%$ \\
UNI-SOL & $92.934 .900,27$ & $21,27 \%$ \\
FSADU & $34.003 .064,23$ & $7,78 \%$ \\
\hline TOTAL & $\mathbf{4 3 6 . 9 8 1 . 9 1 2 , 1 9}$ & $\mathbf{1 0 0 \%}$
\end{tabular}

Fonte: Relatórios de Gestão das Fundações de Apoio

O Tabela 4 evidencia o total $\mathrm{R} \$ 436.981 .912,19$ (quatrocentos e trinta e seis milhões, novecentos e oitenta e um mil, novecentos e doze reais e dezenove centavos) administrados 


\section{A IMPORTÂNCIA DA TRANSPARÊNCIA NA GESTÃO DE RECURSOS PÚBLICOS, EM FUNDAÇÕES DE APOIO A PESQUISA E EXTENSÃO}

em 2007 pelas Fundações de Apoio analisadas. A FUNPAR gerenciou 38,74\% dos recursos, em seguida aparece a FAI-UFSCar com $23,05 \%$ e as demais entidades totalizaram o percentual de 38,21\% da administração dos recursos.

No quadro abaixo são descritas as Demonstrações Contábeis divulgadas pelas entidades pesquisadas:

\section{Quadro 2}

\section{Demonstrações Contábeis}

\begin{tabular}{|c|c|}
\hline FUNDAÇÃO DE APOIO & DEMONSTRAÇÕES CONTÁBEIS E DEMAIS RELATÓRIOS \\
\hline FUNPAR & $\begin{array}{l}\text { - BALANÇO SOCIAL } \\
\text { - BALANÇO PATRIMONIAL } \\
\text { - DEMONSTRAÇÃO DE DÉFCIT/SUPERÁVIT } \\
\text { - DEMONSTRAÇÃO DAS MUTAÇÕES DO PATRIMÔNIO SOCIAL } \\
\text { - DEMONSTRAÇÃO DAS ORIGENS E APLICAÇÕES DOS RECURSOS } \\
\text { - DEMONSTRAÇÃO DO VALOR ADICIONADO } \\
\text { - PARECER DOS AUDITORES INDEPENDENTES }\end{array}$ \\
\hline FAI-UFSCar & $\begin{array}{l}\text { - BALANÇO PATRIMONIAL } \\
\text { - DEMONSTRAÇÃO DO RESULTADO DO EXERCÍCIO } \\
\text { - DEMONSTRAÇÃO DAS MUTAÇÕES DO PATRIMÔNIO LÍQUIDO } \\
\text { - DEMONSTRAÇÃO DAS ORIGENS E APLICAÇÕES DOS RECURSOS }\end{array}$ \\
\hline FUNAPE & $\begin{array}{l}\text { - BALANÇO PATRIMONIAL } \\
\text { - DEMONSTRAÇÃO DE DÉFCIT/SUPERÁVIT } \\
\text { - DEMONSTRAÇÃO DAS ORIGENS E APLICAÇÕES DOS RECURSOS } \\
\text { - PARECER DOS AUDITORES INDEPENDENTES } \\
\text { - PARECER DO CONSELHO CURADOR } \\
\text { - PARECER DO CONSELHO DELIBERATIVO }\end{array}$ \\
\hline UNI-SOL & $\begin{array}{l}\text { - BALANÇO PATRIMONIAL } \\
\text { - DEMONSTRAÇÃO DE DÉFCIT/SUPERÁVIT } \\
\text { - DEMONSTRAÇÃO DAS ORIGENS E APLICAÇÕES DOS RECURSOS }\end{array}$ \\
\hline FSADU & $\begin{array}{l}\text { - BALANÇO PATRIMONIAL } \\
\text { - DEMONSTRAÇÃO DE DÉFCIT/SUPERÁVIT } \\
\text { - DEMONSTRAÇÃO DAS MUTAÇÕES DO PATRIMÔNIO SOCIAL } \\
\text { - DEMONSTRAÇÃO DAS ORIGENS E APLICAÇÕES DOS RECURSOS } \\
\text { - PARECER DOS AUDITORES INDEPENDENTES } \\
\text { - PARECER DO CONSELHO CURADOR }\end{array}$ \\
\hline
\end{tabular}

Fonte: Relatórios de Gestão das Fundações de Apoio

De acordo com a CFC (2008) NBC T 10.4, norma que estabelece critérios e procedimentos específicos de avaliação, registro contábeis e de estruturação das demonstrações contábeis das Fundações, as demonstrações exigidas para este tipo de instituição são as seguintes: 


\section{A IMPORTÂNCIA DA TRANSPARÊNCIA NA GESTÃO DE RECURSOS PÚBLICOS, EM FUNDAÇÕES DE APOIO A PESQUISA E EXTENSÃO}

- balanço Patrimonial;

- demonstração do Superávit ou Déficit;

- demonstração das Mutações do Patrimônio Social;

- demonstração das Origens e aplicação de recursos.

Sendo assim, de acordo com o exposto no quadro 2, constatou-se que a FUNPAR, a FUNAPE e a FSADU evidenciaram todas as demonstrações exigidas, a FAI-UFScar divulgou todas demonstrações, porém a Demonstração do Resultado do Exercício foi apresentada com a nomenclatura exigida pela Lei 6.404/76 e não pela Norma específica das Fundações. A única instituição que não apresentou todas as demonstrações foi a UNI-SOL.

Quanto ao Parecer de Auditoria Independente, somente 60\% das entidades apresentam esse documento.

Quanto a apresentação de Prestação de Contas, a única fundação que fez referência a esta informação no seu Relatório de Gestão foi a FAI-UFSCar, informando que elaborou no total 122 Relatórios de Prestação de Contas às Entidades Financiadoras, sendo 96 relatórios parciais e 26 finais.

Verifica-se nos sites das demais fundações analisadas e não encontra-se nenhuma informação relativa à prestação de contas anual ao Ministério Público, nem dados a respeito de relatórios de prestação de contas às entidades financiadoras.

\section{CONSIDERAÇÕES FINAIS}

Visando o bem da coletividade o Terceiro setor surgiu como grande parceiro do governo na execução de serviços que apresentavam deficiências no âmbito público. Este setor abrange as entidades como Serviços Sociais Autônomos, Organizações Sociais e Organizações da Sociedade Civil de Interesse Público - OSCIP, sua característica essencial é finalidade não lucrativa.

Além de serem financiadas por entidades privadas, as entidades abrangidas pelo Terceiro Setor recebem grande parcela de seus recursos de parceiros governamentais, razão pela qual devem ser utilizados métodos de controle e fiscalização eficazes e bem definidos.

O presente trabalho objetivou evidenciar a transparência nas organizações do Terceiro Setor, tendo em vista o volume de recursos públicos administrados por estas entidades. O tipo de entidades analisadas foram as Fundações de Apoio Instituições de Ensino Superior. São organizações de direito privado, instituídas por pessoas físicas ou jurídicas, que visam auxiliar 


\section{A IMPORTÂNCIA DA TRANSPARÊNCIA NA GESTÃO DE RECURSOS PÚBLICOS, EM FUNDAÇÕES DE APOIO A PESQUISA E EXTENSÃO}

e fomentar os projetos de pesquisa, ensino e extensão das universidades federais e demais instituições de ensino superior, públicas ou privadas.

$\mathrm{Na}$ pesquisa foram analisados os sites das Fundações credenciadas no MEC em busca de informações relevantes para o estudo, sendo escolhidas para a pesquisa as cinco fundações que apresentaram o maior número de dados pertinentes e atualizados.

Foram selecionadas para a pesquisa cinco Fundações de Apoio, uma de cada região do país. A FSADU representando a região nordeste, a UNI-SOL como representante do norte, a FUNAPE do centro oeste, a região sul foi representada pela FUNPAR e a FAI-UFSCar representou o sudeste. Para a realização do presente estudo, foram analisados os Relatórios de Gestão de cada fundação, disponibilizados nos sites das entidades.

Evidenciou-se dificuldade para o agrupamento e análise dos dados divulgados nos relatórios, tendo em vista a falta de padronização na elaboração dos mesmos.

Inicialmente foi avaliado o total de projetos administrados pelas fundações de apoio e deste total, quantos seriam públicos, bem como o total de recursos gerenciados e qual a parcela pública destes valores. A FUNPAR apresentou o maior número de projetos e recursos gerenciados, porém não revelou em seu Relatório de Gestão, o montante de recursos públicos sob sua administração. Somente a FAI-UFSCar e a UNI-SOL apresentaram o valor de recursos públicos por ela gerenciados, representando o somatório destes recursos $19 \%$ do total evidenciado.

Outro fator evidenciado foi que $80 \%$ das entidades apresentaram todas as Demonstrações Contábeis obrigatórias. Quanto ao Parecer de Auditoria independente, que proporciona maior credibilidade às informações divulgadas, foi apresentado por três das cinco instituições analisadas.

E para finalizar a análise, quanto a Prestação de Contas às entidades financiadoras, a única que divulgou informações foi a FAI-UFSCar, anunciando a elaboração de 122 Relatórios de Prestação de Contas no ano de 2007.

Este fato constatado é extremamente relevante para pesquisa, tendo em vista que a Prestação de contas é um ponto fundamental na evidenciação da transparência dos resultados das instituições analisadas e a ausência destes dados demonstra a carência de controle e fiscalização pelos usuários em geral. 


\section{A IMPORTÂNCIA DA TRANSPARÊNCIA NA GESTÃO DE RECURSOS PÚBLICOS, EM FUNDAÇÕES DE APOIO A PESQUISA E EXTENSÃO}

Pode-se concluir baseados na pesquisa realizada que as informações divulgadas pelas Fundações de Apoio deveriam ser expostas de maneira mais clara e objetiva, devendo detalhar informações relativas ao montante de recursos públicos administrados, que foram omitidas em três das cinco fundações analisadas.

Apesar da falta de maiores dados a este respeito, constatou-se um expressivo valor de recursos públicos administrados pelas Fundações em estudo, o que fortalece a premissa da importância do controlar e fiscalizar as referidas entidades. Em função disso, percebe-se a necessidade de maior transparência nas informações destas instituições, pois até mesmo a dificuldade em identificar instituições que forneçam, por meio do seu site informações detalhadas, é uma evidencia da falta de cuidado com a questão da transparência nestas instituições.

\section{REFERÊNCIAS}

ALVES, Antônio Marcos dos Santos; AZEVEDO, Mario Luiz Neves de. Fundação de Apoio a Universidade: Uma discussão sobre o conflito entre o público e o terceiro setor. Atos de Pesquisa em Educação - PPGE/ME FURB. Blumenau, v.2, n 3, p. 486-507, set./ dez. 2007.

ASSIS, Márcio Sanches de; MELLO, Gilmar Ribeiro de; SLOMSKI, Valmor. Transparência nas Entidades do Terceiro Setor: A Demonstração do Resultado Econômico como Instrumento de Mensuração de Desempenho. In: Congresso USP Iniciação Científica em Contabilidade, 3, 2006, São Paulo. Anais...São Paulo. CD-ROM

BETTIOL JUNIOR, Alcides; VARELA, Patrícia Siqueira Varela. Demonstrações Contábeis para Instituições do Terceiro Setor: Um Estudo do Statement of Financial Accounting Standards $\mathbf{n}^{\mathbf{0}} 117$ (FAS 117). In: CONGRESSO USP DE CONTROLADORIA E CONTABILIDADE, 6., 2006, São Paulo. Anais... São Paulo: FEA/USP, 2006. CD-ROM.

BRANCO, Vera Sylvia Venegas Falsetti. Imunidade Tributária e Terceiro Setor: Por maior Transparência e Regulamentação. In: Encontro da ANPAD, 21, 1997, Rio de Janeiro. Anais...Rio de Janeiro. CD-ROM

BRASIL. Constituição da República Federativa do Brasil. Brasília: Senado Federal, 1988.

. Decreto 6.170, de 25 de julho de 2007. Dispõe sobre as normas relativas às transferências de recursos da União mediante convênios e contratos de repasse, e dá outras providências. Brasília, DF. Disponível em <http://www.planalto.gov.br/ccivil_03/_Ato20072010/2007/Decreto/D6170.htm > Acesso em 03/08/2009. 
Lei $n^{0}$ 8.958, de 20 de dezembro de 1994. Dispõe sobre as relações entre as instituições federais de ensino superior e de pesquisa científica e tecnológica e as fundações de apoio e dá outras providências. Brasília, DF. Disponível em $<$ http://www.pedagogiaemfoco.pro.br/18958_94.htm> Acesso em 03/08/2009.

Lei $n^{0}$ 9.790, de 23 de março de 1999. Dispõe sobre a qualificação de pessoas jurídicas de direito privado, sem fins lucrativos, como Organizações da Sociedade Civil de Interesse Público, institui e disciplina o Termo de Parceria, e dá outras providências. Brasília, DF. Disponível em <http://www.planalto.gov.br/ccivil_03/LEIS/L9790.htm> Acesso em 03/08/2009.

. Portaria Interministerial MP/MF/MCT $n^{0}$ 127, de 29 de maio de 2008. Estabelece normas para execução do disposto no Decreto no 6.170, de 25 de julho de 2007, que dispõe sobre as normas relativas às transferências de recursos da União mediante convênios e contratos de repasse, e dá outras providências. Brasília, DF. Disponível em $<$ http://www.conveniosfederais.com.br/Portarias/InterMin127_08_busca_nova.html $>$ Acesso em 03/08/2009.

CASTRO, Domingos Poubel de. Auditoria e Controle Interno na Administração Pública. São Paulo: Atlas, 2008.

CONSELHO FEDERAL DE CONTABILIDADE - CFC. Manual de procedimentos contábeis e prestação de contas das entidades de interesse social. 2. ed. Brasília: CFC, 2008.

CONSElHO FEDERAL DE CONTABILIDADE - CFC. Princípios Fundamentais e Normas Brasileiras de Contabilidade. 3. ed. Brasília: CFC, 2008.

FUNDAÇÃO DE APOIO INSTITUCIONAL AO DESENVOLVIMENTO CIENTÍFICO E TECNOLÓGICO DA UNIVERSIDADE FEDERAL DE SÃO CARLOS. Disponível em $<$ http://www.fai.ufscar.br/ > . Acesso em 20/08/2009.

FUNDAÇÃO DE APOIO INSTITUCIONAL RIO SOLIMÕES. Disponível em $<\mathrm{http}$ ://www.riosolimoes.org.br/ > . Acesso em 21/08/2009.

FUNDAÇÃO DE APOIO A PESQUISA DA UNIVERSIDADE FEDERAL DE GOIÁS. Disponível em $<$ http://www.funape.org.br/ $>$. Acesso em 20/08/2009.

FUNDAÇÃO DE APOIO DA UNIVERSIDADE FEDERAL DO PARANÁ. Disponível em $<$ http://www.funpar.ufpr.br:8088/funpar/ >. Acesso em 20/08/2009.

FUNDAÇÃO SOUSÂNDRADE DE APOIO A UNIVERSIDADE FEDERAL DO MARANHÃO. Disponível em <http://www.fsadu.org.br/ > . Acesso em 21/08/2009.

FURASTÉ, Pedro Augusto. Normas Técnicas para o Trabalho Científico Elaboração e Formatação. $14^{\circ}$ ed. Porto Alegre: 2008. 
KOHAMA, Heilio. Contabilidade Pública: Teoria e Prática. 7. ed. São Paulo: Atlas, 2000.

NUNES, Andrea. Terceiro Setor Controle e Fiscalização. 2. ed. São Paulo: Método, 2006.

PAES, José Eduardo Sabo. Fundações e Entidades de Interesse Social: Aspectos jurídicos, administrativos, contábeis e tributários. 3. ed. Brasília: Brasília Jurídica, 2001.

PETER, Maria da Glória Arrais; MACHADO, Marcus Vinícius Veras. Manual de Auditoria Governamental. São Paulo: Atlas, 2003.

RAFAEL, Edson José. Fundações e Direito. São Paulo: Companhia Melhoramentos, 1997.

RESENDE, Thomas de Aquino. Roteiro do Terceiro Setor. Associações e Fundações: o que são, como instituir, administrar e prestar contas. 3 ed. Belo Horizonte: Prax, 2006.

SILVA, Antonio Carlos Ribeiro. Metodologia da Pesquisa Aplicada à Contabilidade. 2a Ed. São Paulo: Atlas, 2008.

SZAZI, Eduardo. Terceiro Setor: Regulação no Brasil. 4. ed. São Paulo: Peirópolis, 2006.

TRISTÃO, Gilberto. O papel das fundações na modernização das universidades federais. In: V Congresso Internacional del CLAD sobre la Reforma Del Estado y de la Administración Pública, Santo Domingo, Rep. Dominicana, 24-27 Oct. 2000. 


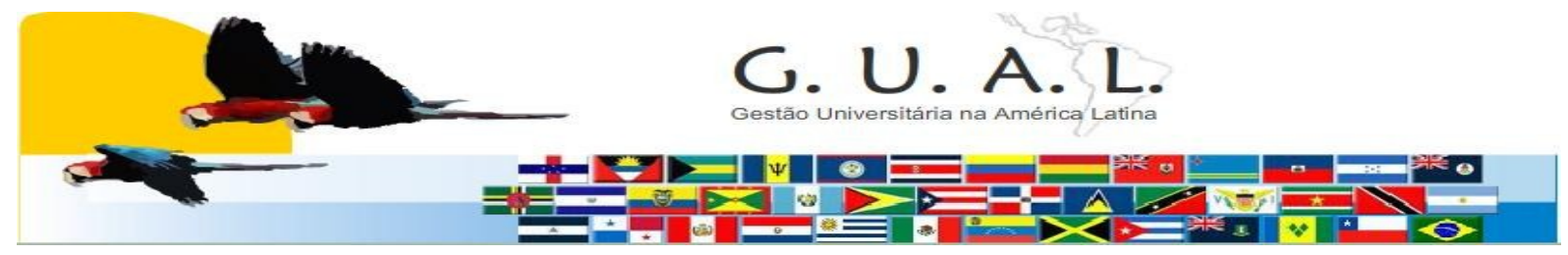

ISSN 1983-4535

\title{
THE IMPORTANCE OF THE TRANSPARENCY IN THE MANAGEMENT OF PUBLIC RESOURCES, FOUNDATIONS OF SUPPORT THE RESEARCH AND EXTENSION
}

Taiane Lemõns Gonçalves, Especialista
Universidade Federal do Rio Grande
tlgoncalves@hotmail.com

Alexandre Costa Quintana, Mestre

Universidade Federal do Rio Grande

quintana@vetorial.net

\begin{abstract}
Given the growth of the Third Sector, this work aims to highlight the importance of transparency in the entities covered by it, given that these institutions and they are financed by private companies, also receive and manage public resources. The third sector covers the nonprofit bodies and have the interest of the community. The focus of the study are the Foundations of Support for Institutions of Higher Education. The methodology used for the development of the work is of an applied nature because it is a field research and analyze the Web sites and reports on Foundations of Management Support in search of data showing the transparency of their actions. Regarding goals is exploratory and descriptive, as the procedures are documentary and field and approach the problem is performed under the qualitative aspect. Since the entities discussed play of social services and that much of the population has no acces to the Internet, the dissemination of activities conduceted and the results should be carried out in media accessible to cociety at large. The results showed a significant number of projects and public funds administered by the Foundations of Support, so it was found that social control is essential and that the information from the websites of foundations should be established with more objective and clear, allowing the analysis and understanding of all stakeholders.
\end{abstract}

Keywords: Third sector. Foundations of support. Transparency 